\title{
A INVENCCÃO DA ZONA SUL: ORIGENS E DIFUSẨO DO TOPÔNIMO ZONA SUL NA GEOGRAFIA CARIOCA
}

\author{
ELIZABETH DEZOUZART CARDOSO ${ }^{1}$ \\ Universidade Estadual do Rio de Janeiro
}

\section{Introdução}

Corrêa (2003), em texto publicado sobre as relações entre o fenômeno urbano e a geografia cultural, trata da importância da toponímia para estes estudos. Em suas palavras (p. 176): "A toponímia constitui-se em relevante marca cultural e expressa uma efetiva apropriação do espaço por um dado grupo cultural. É ainda um poderoso elemento identitário. A toponímia, em realidade, articula linguagem, política territorial e identidade". Mais adiante, neste mesmo texto, Corrêa demonstra, citando Ferreira da Silva, como no Rio de Janeiro o topônimo Tijuca, foi se impondo a várias áreas ao redor deste bairro, fazendo desaparecer outros antigos topônimos. Este fato foi patrocinado pelos promotores imobiliários "desejosos de valorizar os imóveis verticalizados, por meio da venda de um endereço de prestígio para um segmento social procedente, via de regra, de bairros de status social inferior e que via na Tijuca, agora ampliada espacialmente, o lugar de uma identidade social desejada." (CORRÊA, 2003:176-177).

O historiador Da Mata (2005) também nos apresentou argumentos significativos sobre a importância do estudo da toponímia. Em suas palavras:

O nome é sempre muito mais que um signo. Ele está de tal forma amalgamado com aquilo que representa, que nas mais diversas culturas sua escolha nunca é deixada à obra do acaso,

\footnotetext{
${ }^{1}$ Bolsista recém-doutora

Programa da Pós-Graduação em Geografia - UERJ
} 
pois o nome traduz (seríamos quase tentados a dizer produz) a essência de quem ou daquilo que nomeia (DA MATA, 2005:119).

Um topônimo pode carregar uma série de representações e também permitir que em torno dele se estabeleçam identidades que darão a esse lugar ou aos seus moradores, um poder (HALL, 2006). Assim, intimamente ligada às identidades e representações, por si só já interligadas, a toponímia é objeto de estudo que deve ser privilegiado no estudo daquelas categorias relacionadas à formação e à evolução do espaço urbano.

A área da cidade do Rio de Janeiro denominada e conhecida por Zona Sul compreende um conjunto de diferentes bairros dos quais vários estão localizados à beira mar e outros são adjacentes, e que conhecem grande prestígio e valorização imobiliária. O termo Zona Sul no Rio de Janeiro, hoje, é mais que uma simples referência geográfica pois se converteu há algumas décadas num verdadeiro topônimo a designar aquela parte da cidade. Mesmo com a mais recente ocupação da Barra da Tijuca, bairro também praiano e que vem conquistando vários moradores de mais alto status, a Zona Sul ainda permanece, para a maioria da população carioca, como a "utopia urbana", como Velho (1989) chamou Copacabana, onde este fenômeno primeiro se localizou. Isso que se reflete no fato de ser ainda na Zona Sul onde se encontra o mais alto preço do metro quadrado do solo da cidade. $^{2}$ De fato, se Copacabana foi onde primeiro se materializou o objeto do desejo ou "utopia" urbana na cidade do Rio de Janeiro, há décadas a Zona Sul de uma forma geral é este objeto, sendo alguns bairros mais desejados que outros, mas, de uma forma geral, a Zona Sul, pode-se dizer, é a "utopia urbana" no Rio de Janeiro.

À Zona Sul está relacionada uma série de representações, em sua maior parte positivas, mas também negativas. A este topônimo, estão, ou estiveram, até bem pouco tempo, relacionadas representações como de local belo, de alto status, de cosmopolitismo, de elegância, de lançamento de modas e modernidades, de maior liberação de costumes de seus

2 Veja-se, por exemplo, a matéria do jornal $O$ Globo no caderno "Morar Bem", 12/08/2007, intitulada "Caem os mitos da Zona Sul". Ao contrário do que sugere o título, nesta matéria afirma-se que no Leblon o metro quadrado do imóvel está tão alto que as vendas tenderam a ser mais lentas, enquanto em outras áreas as vendas tornaram-se mais rápidas. O título da matéria refere-se ao fato de outro bairro da Zona Sul, o Flamengo, onde havia imóveis mais baratos, estar passando pelo processo de valorização de suas unidades. 
moradores, por vezes associada à representação anterior, e também, por vezes, e pelo mesmo motivo, associada a uma representação de "lugar de perdição" - até bem pouco tempo ou para moradores mais antigos ${ }^{3}$. Outras áreas da cidade, como a Zona Norte e os chamados subúrbios, ao contrário, têm ou tinham a eles relacionadas outras representações como, por exemplo, o conservadorismo dos costumes, a "falta de gosto" ou de elegância de seus moradores, a vida mais pacata ou provinciana que se levava nestes bairros, etc. Este fato se consubstanciou por várias décadas numa verdadeira dicotomia Zona Sul x Zona Norte/Subúrbios no Rio de Janeiro, permitindo àquela zona uma valorização cada vez maior que se reflete na forma de ocupação de seu espaço.

Com os parágrafos anteriores, acreditamos, justifica-se o estudo do surgimento e disseminação do topônimo Zona Sul na cidade do Rio de Janeiro.

\section{O topônimo Zona Sul e o urbanismo}

Em nossa pesquisa procuramos verificar, primeiramente, a possibilidade do termo "zona sul" ter como fonte o urbanismo, devido à presença da palavra "zona". A pesquisa demonstrou, entretanto, que o surgimento daquele termo na cidade do Rio de Janeiro não está relacionado diretamente ao urbanismo e ao zoneamento, pois, de fato, não encontramos nenhuma legislação que tenha dividido a cidade em zonas "geográficas", como Norte, Sul, Oeste etc

Começamos a pesquisa a partir da legislação urbanística, procurando as leis que porventura estivessem pondo em prática algum tipo de zoneamento. A prática do zoneamento já era conhecida tanto nos EUA quanto na Europa desde fins do século XIX e princípios do século XX. Embora a primeira lei de zoneamento para Nova York seja de 1916, ainda no século XIX algumas cidades já realizavam esta prática. O exemplo europeu, no entanto, contribuiu muito para a disseminação deste tipo de diretriz urbanística naquele país a partir da década de 1910. Como esclarece Hall (2002:69):

\section{(...) o zoneamento chegou a Nova York vindo da Alemanha, o que talvez seja o supra-sumo da simplificação: na prática, o}

\footnotetext{
3 “Copacabana, criar filha lá? Criar filha é na Tijuca." Frases de um antigo morador da Tijuca que expressa bem esta percepção (cf. Cardoso, E. D. et alii. [1984], p. 132).
} 
sistema norte-americano de zonear o uso do solo parece ter se originado de uma tentativa de controlar a disseminação de tinturarias chinesas na Califórnia, primeiro na cidade de Modesto e, em seguida, em San Francisco, nos anos 80 do século XIX; e de 1909 em diante, Los Angeles já desenvolvia um zoneamento abrangente de uso do solo. Mas foi o modelo alemão de zoneamento de uso do solo e altura dos edifícios que, importado pela cidade de Nova York quando da aprovação da lei de zoneamento de 1916, constituiu segundo acreditavam os contemporâneos - o mais significativo avanço já registrado na história ainda incipiente do planejamento urbano norte-americano.

$\mathrm{Na}$ pesquisa sobre a legislação urbanística atinente, encontramos o Decreto 1.185 de 05/01/1918, que pode ser considerado a primeira legislação de zoneamento do Rio de Janeiro. Tal decreto dividiu a cidade em zonas urbana, suburbana e rural (FERNANDES, 1995:37). Os bairros que viriam a se constituir na Zona Sul estavam incorporados à zona urbana da cidade. Sobre a zona suburbana:

o que se entendia como território suburbano correspondia ao significado tradicional da palavra. Ela ocupava não aqueles subúrbios mais exemplares como Méier ou Todos os Santos, mas sim o descampado litoral da baía de Guanabara (áreas de brejos, manguezais e suas ilhas); Bangu, um subúrbio industrial e ferroviário; Jacarepaguá, (...); e não menos, as partes montanhosas da Gávea e Tijuca (FERNANDES, 1995:37-38).

Assim, pelo urbanismo, os bairros que comporiam a Zona Sul, sendo alguns deles ainda com uma feição suburbana (no sentido mais tradicional da palavra, pois pouco povoados), como Copacabana, Ipanema e Leblon, estavam incorporados à mesma "zona urbana" da cidade que outros bairros de ocupação mais antiga e densa, não se distinguindo aqueles destes, portanto, neste campo. E interessante, pois, notar como os bairros de Copacabana, Ipanema e Leblon, mesmo que ainda quase descampados, já eram incorporados à zona urbana, o que demonstra claramente um projeto já em curso para esta área, ou seja, de que seria incorporada à malha urbana de forma distinta dos chamados "subúrbios".

Nova legislação, o Decreto 2.087 de 19/01/1925, veio estipular outro zoneamento para a cidade, ficando esta então dividida em quatro zonas: central; urbana; suburbana e rural. Em relação às zonas urbana e suburbana, não houve praticamente alteração de seus limites. Segundo 
Oliveira (1978:5), a zona urbana "correspondia aos assentamentos residenciais mais populosos na época, ou a parte efetivamente 'conhecida e habitada' da cidade. Nesta área estão contidas várias zonas residenciais, inclusive as atuais 1, 2 e 3." Vê-se mais uma vez aí o "equivoco" no tratamento dos bairros praianos ainda pouco ocupados como mais "conhecidos" (por quem?)

É interessante notar que também o "Plano Agache", de fins da década de 1920, não faz referência aos termos zona sul e zona norte, chamando de "bairros burgueses" os da atual zona sul e alguns da zona norte.

O Decreto 6.000 de 1937 estabeleceu novo zoneamento para a cidade, mudando e diversificando mais as funções reconhecidas. No Art. 2, do Título I do Capítulo II, fica estabelecido o seguinte. "Para os efeitos do presente decreto fica o Districto Federal dividido nas seguintes zonas: a Comercial (ZC), a Portuária (ZP), a Industrial (ZI), a Residencial (ZR) e a Rural e Agrícola (ZA)". Nos parágrafos seguintes ficam também estabelecidas subzonas das zonas Central (em número de 3) e Residencial (também em número de 3). O Art. 3 da mesma lei estabelece uma hierarquia das Zonas e partes de Zonas, segundo sua importância. Desta maneira, foi considerada como zona mais importante a ZC1 e depois vinham as ZE (Esplanada do Castelo, subzona da ZC), ZC2, ZP, ZI, ZR1, ZR2, ZR3 e ZA. Os bairros da atual Zona Sul estavam incluídos na ZR1.

Fizemos essa breve revisão da legislação urbanística do Rio de Janeiro, basicamente dos primórdios da legislação sobre zoneamento, no intuito de verificar se o surgimento do termo Zona Sul teria algum respaldo naquelas normas, mas poder-se-ia afirmar apenas que seu surgimento pode ter estimulado a popularização da expressão "zona" numa fase de assentamento deste novo instrumento regulador que se institucionalizava ${ }^{4}$.

\section{O topônimo Zona Sul nos periódicos}

Descartada a origem na legislação urbanística para encontrar a gênese do topônimo "Zona Sul", realizamos uma pesquisa em três

\footnotetext{
${ }^{4}$ É interessante notar a coincidência da utilização do termo zona e da prática do zoneamento em Recife, por exemplo. Como demonstra Lira "Se em 1919, a divisão da cidade seria referida às zonas ou perímetros, em 1936, a noção de zona seria imposta como parte de uma disciplina nova do espaço urbano, o assim chamado, 'zoneamento", (LIRA, J. 2001:201).
} 
periódicos (e de três tipos diferentes). Os periódicos consultados foram os seguintes: o jornal Correio da Manhã, a revista "O Cruzeiro" e o jornal/revista de bairro "Beira Mar".

Nos três periódicos fizemos uma pesquisa nos meses de dezembro, janeiro e fevereiro, nos meses de verão, portanto, onde era esperado encontrar mais referências sobre esta área da cidade uma vez que o costume de frequentar a praia deveria pôr esta área da cidade mais em evidência durante este período.

Iniciamos nossa pesquisa com o jornal Correio da Manhã, pois era um periódico de circulação mais ampla. Neste, além da amostragem dos meses de verão, fizemos uma pesquisa de dois em dois anos.. Neste jornal pesquisamos principalmente a página dos chamados "editoriais", onde eram encontradas, ainda que raramente no período pesquisado, notícias e artigos sobre a cidade, e os classificados. Em alguns exemplares encontramos uma coluna própria para os "subúrbios" coluna esta que, entretanto, teve curta duração.

Apesar de que, de início, segundo nossas hipóteses, pretendíamos pesquisar nos jornais desde princípios do século XX, observamos, fazendo um outro trabalho sobre o Rio de Janeiro e a segregação sócio espacial, segundo os escritos de Lima Barreto (CARDOSO e FERNANDES, 2007) que este autor não utiliza em nenhuma de suas crônicas sobre a cidade o termo zona sul. Ele se refere diversas vezes aos bairros da Zona Sul, nomeando-os um a um e nunca se refere a este termo quando quer falar daquela área. Ao que parece, ele, como os demais escritores, cronistas, jornalistas etc., também distinguia a Zona Sul (e a Zona Norte) dos demais bairros pela palavra arrabaldes, assim diferenciando-a dos subúrbios, como se pode constatar nas seguintes passagens da crônica "O Cedro de Terezópolis", em que fala sobre os ricos: "Os nossos arrabaldes e subúrbios são uma desolação. As casas de gente abastada têm, quando muito, um jardinzito liliputiano de polegada e meia; e as de gente pobre não têm coisa alguma". E, mais adiante, na mesma crônica, falando dos ricos: "Atulham-se em dois ou três arrabaldes que já foram lindos, não pelas edificações, e não só pelas suas disposições naturais, mas também, e muito, pelas grandes chácaras que neles havia. Botafogo está neste caso, Laranjeiras, Tijuca e Gávea também."

A partir desta observação e do fato do Plano Agache também não se referir às zonas sul, norte etc. começamos a pesquisar o Correio da Manhã no ano de 1920 e caso já encontrássemos o termo Zona Sul naquele ano, voltaríamos para trás, até sua primeira referência. Entretanto, só fomos 
encontrar este termo pela primeira vez num exemplar de janeiro de 1940. Antes, porém, em 1930, encontramos uma matéria em que já aparecia a noção de "bairros sul" do Rio de Janeiro. Esta matéria dizia respeito à proibição de çirculação dos ônibus vindos do "norte" e do "sul" da cidade pela Avenidas:

É uma coisa disparatada a providencia que a Inspetoria de Vehiculos resolveu adoptar, a partir do dia 15 do corrente estabelecendo que os omnibus que vêm do ponto sul da cidade voltarão do Phenix, e os que vêm do ponto norte voltarão da praça Mauá.

Pode-se, mesmo, dizer que raramente se concebe uma idea tão absurda, que só será posta em pratica nesta capital, porque, infelizmente, as nossas autoridades superiores não se incommodam com os interesses populares.

Actualmente, por exemplo, qualquer morador de Copacabana, póde viajar directamente de lá até a praça Mauá. A Inspetoria de Vehiculos acaba com isso. Quem quiser vir de Copacabana, de Botafogo ou de Laranjeiras para o Cáes do Porto terá de saltar na Avenida e esperar outro omnibus ... se não quiser tomar um táxi ou marchar a pé...

Outro inconveniente é este: os moradores dos bairros sul podem tomar a sua conducção bem pertinho, no Phenix, emquanto os dos bairros norte terão de ir até a praça Mauá. (grifos nossos).

A primeira vez que o termo "zona sul" surgiu no Correio da Manhã foi somente em 1940, de forma que parece que, havia pouco tempo que estava fazendo parte do cotidiano da cidade, mas ainda não estava bem firmado enquanto topônimo, referindo-se apenas a uma área da cidade. Em matéria intitulada "Uma relíquia..." 6 , assim se lê:

As pessoas que transitam pela Avenida Beira-Mar, e constituem grande parte da população carioca que mora na chamada zona sul, vêm assistindo à demolição da ponte adjacente à parte daquella via publica que defronta os fundos do palácio do Cattete. Breve deixará pois de existir uma tradição da cidade... (grifos nossos).

${ }^{5}$ Correio da Manhã, 07/01/1930.

${ }^{6}$ Correio da Manhã, 21/01/1940. 
Poucos dias depois, no entanto, nova matéria já traz o termo zona sul de maneira que parece definitivamente incorporado ao cotidiano da cidade, embora não se constituindo ainda num verdadeiro topônimo, como atualmente. A matéria intitulava-se "O alargamento do Tunnel Novo"7 e dizia o seguinte: “(...) As medidas postas em pratica para facilitar o trafego de vehiculos na zona sul são todas acertadas e louváveis." (grifos nossos).

No entanto, levamos a pesquisa nos classificados mais adiante, assim como pesquisamos em outros periódicos para verificar quando surgiriam nesta parte dos jornais as colunas "Zona Sul" e "Zona Norte". Desde o início da nossa pesquisa, ou seja, 1920, e por muito tempo ainda, os classificados de imóveis apresentavam uma coluna "Subúrbios" e os bairros das chamadas zonas norte e sul vinham em ordem alfabética, sem um título geral que os localizasse em termos de "zonas" da cidade. No Correio da Manhã só surgiram nos classificados as colunas Zona Norte e Zona Sul em $1970^{8}$. Mas, bem antes disso, o Jornal do Brasil inaugurara suas seções de Zona Norte e Zona Sul nos classificados, em $1959^{9}$, e O Globo introduziu estas colunas pouco tempo antes do Correio da Manhã, em $1968^{10}$.

Deve-se mencionar também que realizamos uma pesquisa na coleção de fotografias do Correio da Manhã que atualmente se encontra disponível no Arquivo Nacional. Pesquisando pelas "entradas" zona sul e zona norte, encontramos fotos assim classificadas somente a partir de meados da década de 1950, não se podendo afirmar, entretanto, que só então estes termos passaram a ser efetivamente empregados, mas pressentimos, sim, a possibilidade de que só a partir dessa época aquele jornal passou a ter mais reportagens sobre a cidade.

Pesquisamos depois a revista "O Cruzeiro", desde seu lançamento, em 1928, até 1960. Esta, embora tenha se mostrado muito interessante no que se refere à construção de representações sobre a zona sul carioca, raramente em suas reportagens traz esta expressão. A primeira vez que encontramos referência à Zona Sul foi apenas em um conto de David

\footnotetext{
${ }^{7}$ Correio da Manhã, 23/01/1940.

${ }^{8}$ Correio da Manhã 17/03/1970.

${ }^{9}$ Jornal do Brasil, 01/9/1959.

${ }^{10}$ O Globo 01/10/1968.

${ }^{11}$ Estas fotos, em geral, eram para uma coluna chamada "Gerico" onde se mostravam problemas da cidade, como, por exemplo: calçadas e calçamentos destruídos, falta d'água, postes destruídos, etc.
} 
Nasser de $1943^{12}$, em que o autor se refere às zonas norte e sul da cidade: “(...) Devo explicar ao senhor editor a nossa profissão. Nossa, quer dizer, a minha e a de Bignight. Somos ladrões, 'chameurs' desempregados por falta de serviço, desde que acabaram os 'black-outs' da Zona Norte e aumentou a vigilância na Zona Sul".

Os termos zona sul e zona norte são pouquíssimos utilizados nesta década na revista, só aparecendo mais freqüentemente após 1950, quando proliferam as reportagens fotográficas sobre a Zona Sul, seus bairros e suas praias. Porém, em matéria de 21/01/1948, intitulada "Ramos - 40 graus à sombra", uma reportagem fotográfica de Jean Manzon, a matéria não apenas cita o termo, mas, também explicita o que é concebido como tal: "Quem frequienta as praias da zona sul, as praias limpas, policiadas, que se estendem do Flamengo ao Leblon (...)". Assim, conclui-se que, para muitos, a chamada zona sul era mais ampla, ou seja, ia além de Copacabana, Ipanema e Leblon como concebida a princípio, como veremos adiante.

No(a) jornal/revista Beira-Mar, encontramos a primeira referência também relativamente à localização sul e, logo depois, o termo "zona sul". Este termo, no entanto aparece aí, mais de uma década antes do que no Correio da Manhã. Uma matéria de 1927, já se referia aos "bairros sul". A primeira matéria encontrada referente aos "bairros sul" tratava do problema das favelas na cidade e, particularmente na Zona Sul, dos problemas de saneamento das habitações nelas localizadas e dos planos da prefeitura de dotá-las deste melhoramento. Criticando as péssimas condições de saneamento das favelas existentes na área, o que fazia com que proliferassem doenças, afirma o texto ${ }^{13}$ : “(...) Os bairros sul (Botafogo, Copacabana, Ipanema, Gávea, etc.) fornecem todos os annos uma alta quota de syndromes dysenteri-formes que o inquérito epidemiológico pode perfeitamente desvendar (...)" (grifos nossos).

Poucos dias depois, uma reportagem sobre a futura abertura do Corte de Cantagalo como resposta às necessidades de descongestionamento do tráfego na área que vinha se povoando rapidamente, encontramos a primeira referência ao termo "zona sul" neste periódico $^{14}$ :

\footnotetext{
${ }^{12}$ Bignight o Sorriso 1001, em "O Cruzeiro", 4/12/1943.

${ }^{13}$ O "De Profundis" das Favellas de Copacabana. In: Beira-Mar, 23/01/27.

${ }^{14}$ A nova estrada do Cantagallo. In Beira-Mar, 06/02/1927.
} 
Á proporção que o nosso bairro vae dilatando, numa prosperidade sempre ascencional, mais urgentes e inadiaveis se vão tornando as suas obras de ligação com outros bairros.

Todos sabem a expansão da zona sul, onde os terrenos estão se valorisando de forma incrível, desde o principio de Ipanema e fins de Copacabana, até as áreas do Leblon.

A necessidade de facilitar as communicações naquellas quadras agora popularíssimas levou a Prefeitura a abrir uma nova estrada que, partindo da rua Sá Ferreira corta uma aba do morro do Cantagallo e vae terminar em Ipanema, na rua Vinte de Novembro, tornando assim mais rápidas as communicações entre os quarteirões próximos da Lagôa Rodrigo de Freitas, no Ipanema, e a zona propriamente de Copacabana. (...) (grifos nossos).

Esta última citação mostra a popularização do emprego da palavra "zona" mas nos deixa confusos sobre o que era considerado como "zona sul". Seria somente Copacabana, Ipanema e Leblon? Embora na primeira citação sejam considerados como fazendo parte dos "bairros sul", os bairros de Botafogo e Gávea, dois bairros de ocupação antiga, o que se pode constatar é que, a princípio não havia consenso sobre o que era esta chamada "zona sul". Em matéria veiculada pelo "Beira-Mar" em 1942 sobre as arrecadações que a Associação Comércio e Indústria de Copacabana faria para doar uma avião para a FAB (lembre-se que era período de guerra), afirmava-se que, para tal, a "zona sul" seria dividida em quatro setores: 1) Leme; 2) Leblon; 3) Ipanema; 4) Copacabana, ou seja, os bairros que viriam a ser chamados de "nova zona sul".

Entretanto, em reportagem de "O Cruzeiro" sobre a praia de Ramos, em janeiro de 1948, a chamada zona sul já abrangia uma extensão maior: "Quem freqüenta as praias da zona sul, as praias limpas e policiadas, que se estendem do Flamengo ao Leblon (...).

Porém, o termo "zona sul” não abrangia ainda, para alguns, pelo menos, toda a área que hoje lhe é reconhecida, segundo uma crônica de Rachel de Queiroz, publicada na mesma revista em 1954. Nesta crônica, a autora trata dos costumes na praia do Flamengo e os diferencia dos da "zona sul" "17. "(..) As senhoras usam em geral roupas de banho feitas em casa e, se não chegam à decorosidade perfeita dos 'costumes de banho' do

\footnotetext{
${ }^{15}$ Bombardeio 7 de setembro, in: Beira-Mar 05/12/1942.

${ }^{16}$ Ramos - 40 graus à sombra, in "O Cruzeiro", 21/01/1948

${ }^{17}$ Praia do Flamengo, in: "O Cruzeiro”, 16/01/1954.
} 
começo do século, estão a léguas das audácias impudicas das matronas que se exibem na zona sul" (grifo nosso).

Como se depreende desta frase, para a autora, provavelmente a "zona sul" era composta apenas pelos bairros praianos da "nova zona sul". Compreensão bem diferente da geógrafa Ruth Simões (1952-53) que, pouco tempo antes, escrevendo sobre o bairro de Laranjeiras, localiza os bairros de Botafogo e Gávea (e, provavelmente, embora não explicitamente, Laranjeiras) na "zona sul" e os de Tijuca e Grajaú na "zona norte" (SIMÕES, 1952-53:179 e 203), colocando limites mais amplos do que seria essa chamada "zona sul" e mostrando uma simultaneidade no surgimento dos dois termos, no meio acadêmico como o fora nos classificados.

\section{O topônimo Zona Sul na geografia}

Passemos, então, aos geógrafos que estudaram a cidade e veremos também que a incorporação e definição do que seria a "zona sul" seria bem lenta e gradual. Para nos nortear nesta pesquisa, tomamos o trabalho de Abreu (s/d) que realizou um grande levantamento e uma análise sobre o estudo geográfico da cidade no Brasil e, por consequiência, organizou uma vasta bibliografia sobre a geografia carioca. Aproveitamos as referências bibliográficas deste trabalho para levantar os trabalhos de geógrafos sobre esta cidade, principalmente os mais antigos. Assim, encontramos uma situação parecida com a verificada em jornais de grande circulação. Primeiro, encontraram-se referências a esta parte da cidade como localizada ao sul; depois, surgiu o termo "zona sul", junto com "zona norte" e, por fim, lhes é dada uma definição "científica" e assim passa a ser definitivamente incorporado ao "jargão" geográfico.

Em artigos de Backheuser publicados em 1945 (BACKHEUSER, 1945 a e b) já surgem as localizações norte e sul da cidade, sendo que a sul correspondia a parte da atual "zona sul" e a norte às áreas que posteriormente seriam definidas na geografia como "zona suburbana" ou simplesmente subúrbios. Em um de seus textos Backheuser (1945a:410) afirma:

(...) A cidade, quase tôda na planície, serpeia para o sul, desde Flamengo (4) até Copacabana (3) e Lagoa Rodrigo de Freitas (2). Mas também se alarga para o norte, onde consegue ocupar áreas de certa vastidão, quer na região de Inhaúma (12) e Cascadura (13), onde ficam o Méier e outros prósperos e densos subúrbios da Central, quer em outra 
direção para a ponta do Caju (8) e Penha (9), no setor dos subúrbios da Leopoldina" (grifos nossos).

De fato, Backheuser utiliza pela primeira vez o termo "zona norte" em outra publicação, logo posterior, relacionando-a com a área então conhecida como "subúrbios" enquanto ainda não utiliza o termo zona sul e sim "lado sul", para se referir a parte do que seria conhecido como "zona sul", e "flanco norte", indiferentemente, para bairros que seriam da"zona norte"e da "zona suburbana"no seguinte texto (BACKHEUSER, 1945b:735-736):

Segundo o gráfico de Otto Quelle, o ano de 1899, no qual se define a febre de encilhamento, já estavam larga e efetivamente ocupadas as áreas de Botafogo, do lado sul, e, no flanco norte, as da Tijuca, São Cristóvão, Andaraí, Vila Isabel, Engenho-Novo e Méier. Seguramente a população ainda não estaria adensada, como hoje, mas todo esse, amplo e contorcido polígono já teria efetivo aspecto de verdadeira cidade.

Mas nos trinta anos que se seguem, estes já na República, particularmente depois da presidência de Rodrigues Alves e da inesquecível administração Pereira Passos, o crescimento em superfície é muitíssimo maior. Não só marcam a gigantesca dilatação (...) para as bandas dos subúrbios da Central e da Leopoldina (zona Norte), como significam a valiosa 'conquista de espaço' do Leme, Copacabana, Ipanema e Leblon, ou seja de toda a grande 'cidade oceânica' que é atualmente um dos grandes orgulhos do Distrito Federal (grifos nossos)

É interessante lembrar que, nesta época, já havia uma longa tradição de zoneamento urbanístico da cidade, mas nunca levando em consideração aspectos geográficos e sim de caráter funcional. Mas deve-se lembrar também que não foi na Geografia.que encontramos pela primeira vez o termo "zona sul" e sim num jornal de bairro, quando provavelmente começou a ser incorporado ao cotidiano dos moradores daquela área ou, melhor dizendo, de parte dela. Ao que parece, a Geografia vinha apenas incorporando vaga e imprecisamente uma denominação que passava ao senso comum na cidade.

Depois de Backheuser, retornaremos a Simões que, em princípios da década de 1950, já utilizava os termos "zona norte" e "zona sul" na forma na qual ficaram consagrados por muito tempo, tanto no senso 
comum como na Geografia. Neste trabalho, ela afirma (SIMÕES, 195253:179):

(...) Ao lado do aspecto ligado às chácaras, Laranjeiras teve também no século passado, como arrabalde da cidade, uma função industrial. É que, em 1886, se instalara no sítio do atual Jardim Laranjeiras, uma fábrica de tecidos, como tantas outras existentes nessa época, quer na zona norte, na Tijuca, principalmente, quer nos arrabaldes ${ }^{18}$ da zona sul, na Gávea e Botafogo. (...) (grifos nossos).

Assim, também, alguns anos depois, em 1959, Lysia Bernardes em famoso estudo sobre a evolução da paisagem urbana do Rio de Janeiro até o início do século XX, trata daquelas áreas da cidade chamando-as "zonas sul e norte", reafirmando a incorporação destes termos à geografia carioca. Em suas palavras (BERNARDES, 1959:17):

A vinda da Família Real e poucos anos depois a proclamação da Independência tinham ampliado consideravelmente a função administrativa do Rio de Janeiro que experimentou, então, notável surto de crescimento. (...)

Em direção à orla oceânica a aglomeração perde no entanto seu caráter compacto e se rarefaz, adquirindo forma de certo modo linear, ao longo de suas pontas de lança nas praias, nos vales e nos sopés de encostas na zona sul, o mesmo sucedendo na zona norte. (grifos nossos).

No ano seguinte, um longo trabalho de Geiger (1960) utiliza diversas vezes os termos "nona norte" e "zona sul" e dá um esboço de conceituação geográfica a eles, situando estas "zonas" relativamente a um acidente geográfico e não em relação a suas posições relativas ao Centro da cidade. Isso surgiu na seguinte passagem (GEIGER, 1960:6):

Assim como em algumas grandes capitais do mundo (Paris, Londres, Nova Iorque, Budapeste, etc.) um rio divide a cidade em partes bem distintas, assim a montanha, divide o Rio em zona norte e zona sul, com o agravante de que é mais cômodo construir pontes do que túneis e que, de certo modo,

\footnotetext{
${ }^{18}$ Observe-se que se utiliza a palavra arrabaldes e não subúrbios, demonstrando mais uma vez que, como observa Fernandes (1995), parece que havia um "veto" à utilização da palavra subúrbio para se referir aos bairros da "zona sul", mesmo quando eles ainda tinham características de subúrbios.
} 
os rios se prestam à circulação. Dividido pela serra da Carioca, o Rio de Janeiro se fragmenta em bairros situados em vales, em restingas litorâneas, de ligações, por vêzes estreitas, com todos os problemas da circulação nas passagens" (grifos nossos)

Entretanto, Geiger, em outras passagens de seu texto, mais especificamente em legendas de fotografias, vai se referir à "chamada zona sul" e à "chamada zona norte" e, ainda por cima, entre aspas, fazendo parecer que os termos não estavam ainda bem consolidados ou bem conceituados. Sobre a praia do Flamengo, assim se refere (GEIGER,1960:19): “ A praia do Flamengo funciona como verdadeira via perimetral por onde se faz a circulação automobilística entre o centro da cidade e os bairros da chamada 'zona sul"'. Assim também, em legenda referindo-se ao bairro do Maracanã, afirma (p. 23): "A canalização da planície situada a nordeste do maciço da Tijuca permitiu maior urbanização da chamada 'zona norte"”' (grifos nossos).

O trabalho de Geiger, portanto, apesar de poder parecer pouco firme e definitivo neste aspecto, contribui muito para a fixação destes termos na Geografia. Termos estes que, entretanto, vinham já experimentando largo uso no cotidiano. Geiger, no entanto, dá-lhes uma característica de "cientificidade", situando "geograficamente" o norte e o sul relativamente ao Maciço da Carioca, no que seria acompanhado, pouco tempo depois por Bernardes (1961 e $\left.1987^{19}\right)$. Neste trabalho, Bernardes cita várias vezes as "zonas norte e sul" assim como lhes dá uma delimitação geográfica. É interessante notar também que utiliza aqueles termos em letras maiúsculas, representando, pois, a criação de topônimos, além de mera localização geográfica. Assim, sobre a "zona sul", afirma a geógrafa (1987:92):

A Zona Sul, constituída pelos bairros que se dispõem ao sul do maciço litorâneo e ocupam vales e planícies entre este e o mar, vem merecendo há algumas décadas a preferência da população abastada e de grande parte da classe média, que aí procuram instalar sua moradia, atraídas inicialmente pela proximidade das praias, pelo clima mais fresco, pelas belas paisagens onde o mar ou a montanha estão sempre presentes (grifos nossos).

${ }^{19}$ O texto original é de 1961, mas foi transcrito também em Bernardes e Soares (1987) e esta foi a edição consultada. 
Neste trabalho, os termos "zona sul" e "zona norte" aparecem em maiúsculas e, portanto, como topônimos na seguinte passagem (1987:96): "Todas as formas de expansão do espaço urbano acima referidas, na Zona Sul como na Zona Norte, possuem um caráter comum" (grifos nossos).

Sobre a "zona norte" e sua delimitação em relação à "zona suburbana", Bernardes também nos dá uma característica geográfica. Isso aparece numa legenda de uma fotografia aérea que cobre estas áreas (1987:99):

Os bairros da zona norte - Tijuca, Andaraí, Vila Isabel e Grajaú - separam-se dos da zona suburbana por um alinhamento de cristas bem visível na foto. Além deste limite constituído pela Serra do Engenho Novo e morro do Telégrafo, formaram-se os primeiros subúrbios cuja expansão é evidenciada na foto. (...) (grifos nossos).

Portanto, este trabalho de Bernardes (1987[1961]), vem consagrar a divisão da cidade em "Zona Sul", "Zona Norte" e "Zona Suburbana", como já era reconhecido no cotidiano pela sua população e ficaria conhecido também nos meios acadêmicos por algumas décadas. Com os geógrafos houve uma "invenção da tradição", ou seja, deu-se contornos científicos a uma prática de consenso da população.

\section{O topônimo Zona Sul na música popular}

É de 1959, também, uma música que veio consagrar o termo "Zona Sul" no cotidiano e na toponímia carioca. "Balanço Zona Sul", de autoria de Roberto Menescal, fruto do movimento da "Bossa Nova", surgido naquela área da cidade e no seu auge, veio confirmar a utilização do termo por uma parcela ampla dos moradores da cidade assim como contribuir para difundi-lo ainda mais. Assim canta uma parte desta música:
Balança toda pra andar
Balança até pra falar
Balança tanto
Que já balançou meu coração
Balança mesmo que é bom
Do Leme até o Leblon
E vai juntando 
Um punhado de gente

Que sofre com o seu andar

(...)

É também do início dos anos 1960 (CASTRO, 1990:273) a música "Rio", composta pelo mesmo Menescal e por Ronaldo Bôscoli, que enfatiza a localização "sul" para os bairros praianos. Assim ela canta:

Rio que mora no mar

Sorrio com o meu Rio que tem no seu mar

Lindas flores que nascem morenas em jardins de sol

Rio serras de veludo

Sorrio com meu Rio que sorri de tudo

Que é dourado quase todo dia

E alegre como a luz

Rio é mar

Eterno se fazer amar

O meu Rio é lua

Amiga, branca e nua

É sal, é sol é sul,

São mãos se descobrindo em tanto azul

Por isso que o meu Rio da mulher-beleza

Acaba num instante com qualquer tristeza

Meu Rio que não dorme porque não se cansa

Meu Rio que balança

Sou Rio, sorrio

Sou Rio, sorrio

Verificou-se, assim, que a música popular também deu sua contribuição para a sedimentação do topônimo Zona Sul.

\section{Considerações finais}

Ao contrário daquilo que se imagina e do que nos fazem supor mesmo os estudos urbanos sobre o Rio de Janeiro, o termo Zona Sul demorou muito tempo a ser definitivamente incorporado na toponímia da cidade e isso se deu durante a efetiva incorporação à malha urbana de parte 
desta área e o crescimento dos novos bairros nela situados (Copacabana, Ipanema e Leblon) assim como com a modificação da feição dos bairros que dela fazem parte e são de ocupação mais antiga, dos quais as fábricas foram sendo expulsas, possibilitando a gentrificação destas áreas (como, por exemplo, nos bairros de Jardim Botânico, Gávea e Laranjeiras).

É interessante destacar que, na construção deste termo, primeiro situou-se a localização ao "sul" e depois o surgiu o termo "zona sul", até chegar-se ao topônimo "Zona Sul", difundido para uma população maior da cidade, junto com o topônimo "Zona Norte"20. Este último topônimo, agregava bairros que não eram da Zona Sul mas que também não se confundiam com os "Subúrbios", sendo estes últimos identificados como a longa faixa de terras ao longo das ferrovias desde princípios do século XX, quando se deu o que Fernandes (1995) chamou de rapto ideológico da categoria subúrbio no Rio de Janeiro, ou seja, quando o termo subúrbio passa a designar uma área da cidade de forma deslocada de seu sentido original, com intenção de desqualificá-la, uma vez que, a partir da Reforma Passos, passou a ser ocupada por camadas sociais de mais baixa renda.

O topônimo Zona Sul, nas primeiras décadas do século XX, denominava apenas a área ocupada pelos novos bairros chamados "aquém túneis" pela Revista Beira-Mar (como Copacabana, Ipanema e Leblon, com acesso ao restante da cidade via túneis), cuja ocupação se fazia com casas e apartamentos modernos e, principalmente, por membros de camadas de alta renda, constituindo-se numa área de auto-segregação das classes abastadas na cidade (VILLAÇA, 1998). Provavelmente por esta razão, ou seja, na intenção de valorizar outras áreas, o topônimo Zona Sul foi se estendendo para outros bairros de ocupação mais antiga, contíguos àqueles, e que, depois da década de 1960, quando se construíram os túneis Rebouças e Santa Bárbara, passaram a ser "aquém túneis" também. Esta noção de que a Zona Sul é a área situada "aquém túneis" permanece nos dias atuais.

É importante destacar que o termo "zona sul" surgiu localmente, incorporando-se lentamente ao cotidiano de uma porção mais vasta da população e se firmando, não apenas como topônimo, mas também em seus limites geográficos mais amplos, até chegar ao que hoje é considerado

\footnotetext{
${ }^{20}$ Deve-se notar que devia haver uma grande confusão para a incorporação do termo Zona Norte no cotidiano e nos meios científicos pois o que vinha sendo chamado assim, por exclusão da Zona Sul e dos Subúrbios, eram bairros que ficavam, de fato, a oeste do Centro. Com a definição das Zonas Sul e Norte feita pelos geógrafos a partir de um maciço, passou a ficar mais clara a denominação.
} 
como "Zona Sul", durante a década de 1950, culminando com sua elevação ao status de conceito "científico" e incorporação definitiva ao "jargão" geográfico em princípios da década de 1960. Os trabalhos dos geógrafos vieram apenas consagrar uma divisão da cidade que vinha sendo construída havia algumas décadas pelos seus moradores e a mídia. A partir daí passa a ser comum encontrar os termos "zona norte" e "zona sul" tanto em trabalhos geográficos como nos trabalhos de historiadores que proliferaram durante as comemorações do IV Centenário da cidade do Rio de Janeiro, em 1965, como o bastante difundido livro de Cruls (1965), por exemplo.

É digno de nota também que os termos "zona sul" e "zona norte" não surgiram quando do rapto ideológico da palavra subúrbio pois, até então, ambas as áreas eram reconhecidas como fazendo parte da "área urbana" da cidade. O surgimento e a consolidação do uso destes termos, portanto, fizeram-se necessários à medida que a cidade foi se desenvolvendo de uma forma mais desigual e segregada, necessitando assim diferenciar os bairros da antiga "zona urbana", ou seja, a "zona norte" da "zona sul", à qual se atribuía mais alto status.

Aquele fato ocorreu quando a Zona Sul estava em franco processo de valorização, havendo já Copacabana se tornado na "utopia urbana", objeto de desejo enquanto local de moradia e lazer de grande parte da população e mesmo objeto de desejo enquanto local de turismo internacional, e objeto de novo surto de especulação imobiliária que levou à acentuação da verticalização e à construção dos primeiros apartamentos conjugados. Como tratamos na introdução, o topônimo Zona Sul permitiu também com sua criação e difusão, a constituição e difusão de uma identidade dos moradores desta parte da cidade. No Beira-Mar, várias vezes pudemos encontrar o termo "aquém túneis", enquanto marco territorial para esta identidade da Zona Sul, com representações extremamente positivas sobre a área. Estas representações e esta identidade proporcionaram àquela parte da cidade um poder, que vem até os dias atuais, de pressionar o poder público para obter os melhoramentos com os quais sempre é agraciada.

\section{A INVENÇÃO DA ZONA SUL:ORIGENS E DIFUSÃO DO TOPÔNIMO ZONA SUL NA GEOGRAFIA CARIOCA}

Resumo: Este artigo é resultado de uma pesquisa sobre as origens e a difusão do topônimo Zona Sul na cidade do Rio de Janeiro e suas implicações sobre a geografia da cidade, uma vez que em torno de um topônimo se aglutinam representações e pode surgir uma identidade do 
lugar. Empreendeu-se uma pesquisa na legislação urbanística, em três periódicos distintos, nos textos geográficos e na música popular, com o objetivo de verificar o surgimento do topônimo Zona Sul no Rio de Janeiro. Verificou-se que a difusão e consolidação daquele topônimo ocorreram quando a Zona Sul estava em franco processo de expansão e valorização, afirmando-se como área de auto-segregação das camadas mais abastadas da cidade. O bairro de Copacabana, nela situado, quando da consolidação do topônimo, já havia se tornado, na "utopia urbana", objeto de desejo enquanto local de moradia e lazer de grande parte da população e destino turístico internacional, ensejando um novo surto de especulação imobiliária que levou à acentuação da verticalização e à construção dos primeiros apartamentos conjugados. Isso acabou por incentivar a difusão do topônimo para outros bairros adjacentes. O surgimento do topônimo Zona Sul permitiu também, com sua criação e difusão, a constituição e expansão de uma identidade dos moradores desta parte da cidade, a princípio restrita a alguns bairros e depois difundida para outros. No periódico Beira-Mar, jornal local, várias vezes pudemos encontrar o termo "aquém túneis", para definir esta identidade da Zona Sul com representações extremamente positivas sobre a área. Estas representações e esta identidade proporcionaram àquela parte da cidade um poder, que vem até os dias atuais, de pressionar o poder público para obter os melhoramentos com os quais sempre é agraciada.

Palavras-chave: toponímia; geografia urbana; geografia cultural; Rio de Janeiro

THE INVENTION OF SOUTH ZONE: ORIGINS AND DIFFUSION OF THE TOPONYM “ZONA SUL” IN THE CARIOCA GEOGRAPHY

Abstract: The article is the result of a research about origins and diffusion of the toponym "South Zone" in the city of Rio de Janeiro, and its implications concerning the urban geography, as a toponym implies meanings, and an identity for a given place may arise. Research was made through urban legislation, during three different periods, in geographic texts and in popular music, aiming at spotting the appearance of the toponym "South Zone" in Rio de Janeiro. It was found that the diffusion and consolidation of that toponym occurred when the South Zone was clearly growing and prices were going up, affirming itself as an area of self-segregation for the more affluents. Copacabana district, located therein, when the toponym consolidated, had already become an "urban utopia", object of desire for much many in terms of living and leisure even a destination for international tourism - and subject of a new boom in the property market, leading to an increase in the height of buildings and 
the appearance of the first studio apartments. This helped spreading the toponym to neighbourhoods. Appearance of the toponym South Zone also allowed, along with its creation and diffusion, the constitution and diffusion of an identity common to the inhabitants of this part of the city, first restricted to some districts, later extended to others. In the publication "Beira-Mar", a local newspaper, the expression "before-tunnels" was found several times to define this identity of the South Zone with highly positive representations of this area. These representations and identity conferred a power to that part of the city, still in force today, to press the authorities in order to obtain the improvements with which it is always endowed.

Key words: toponymy; Urban Geography; Cultural Geography; Rio de Janeiro

\section{BIBLIOGRAFIA}

ABREU, Maurício de A s/d. O estudo geográfico da cidade no Brasil: evolução e avaliação (contribuição à história do pensamento geográfico brasileiro). (mimeo)

1987. Evolução urbana do Rio de Janeiro. Rio de Janeiro: IPLANRIO/Zahar

BACKHEUSER, Everardo. 1945. A planta atormentada da cidade. Boletim Geográfico 2 (16).

1945. Crescimento da cidade do Rio de Janeiro. Boletim

Geográfico 3 (29)

BERNARDES, Lysia M. C. 1959. Evolução da Paisagem Urbana do Rio de Janeiro até o início do século XX. Boletim Carioca de Geografia 12 $(1 / 2)$.

. 1987. Expansão do Espaço Urbano do Rio de Janeiro. Revista Brasileira de Geografia, 23 (3). 1961. pp. 495-524. Transcrito em Bernardes, Lysia M. C. e Soares, Maria Therezinha S. Rio de Janeiro Cidade e Região. Rio de Janeiro: Prefeitura da Cidade do Rio de Janeiro/ Secr. Municipal de Cultura: Dep. Geral de Inf. Cultural.

CARDOSO, Elizabeth D. ALBERNAZ, M. P. AIZEN, M, PECHMAN, R., VAZ, L.F. 1983. História dos Bairros - Botafogo. Rio de Janeiro: Index/João Fortes Engenharia.

1986. História dos Bairros - Copacabana. Rio de Janeiro: Index/João Fortes Engenharia. 
CARDOSO, Elizabeth D. e FERNANDES, Nelson.da N. 2007. Lima Barreto e uma outra geografia social do Rio de Janeiro: revendo o processo de segregação da cidade. Anais do VII Encontro Nacional da ANPEGE, Niterói, UFF.

CASTRO, Ruy. 1990. Chega de saudade. São Paulo: Companhia das Letras.

CORRÊA, Roberto L. 2003. A geografia cultural e o urbano. In: CORREAA, R.L. e ROZENDHL, Z. Org. Introdução á geografia cultural. Rio de Janeiro: Bertrand Brasil.

CRULS, Gastão. 1965. Aparência do Rio de Janeiro. Rio de Janeiro, Livraria José Olympio Editora.

DA MATA, Sérgio. 2005. O desencantamento da toponímia. In: CORREAA, R.L. e ROZENDAHL, Z. Org. Geografia: temas sobre cultura e espaço. Rio de Janeiro: EdUERJ.

DUNLOP, C. J. 1957. Subsídios para a história do Rio de Janeiro. Rio de Janeiro: Rio Antigo Ltda.

FERNANDES, Nelson da N. 1995. O Rapto Ideológico da Categoria Subúrbio: Rio de Janeiro (1858-1945). Dissertação de Mestrado. Rio de Janeiro: PPGEO/UFRJ.

GEIGER, Pedro Pinchas. 1960. Ensaio para a estrutura urbana do Rio de Janeiro. Revista Brasileira de Geografia 22(1).

HALL, Peter. 2002.Cidades do Amanhã. Uma história intelectual do planejamento e do projeto urbanos no século XX. São Paulo: Editora Perspectiva.

LIRA, José T. C. de 2001..Freguesias morais e geometria do espaço urbano. O léxico das divisões e a história da cidade. In: Bresciani, M. S. org. Palavras da Cidade. Porto Alegre: Editora da Universidade. p. 157209.

OLIVEIRA, Lígia G. 1978. Desenvolvimento Urbano da Cidade do Rio de Janeiro; uma visão através da ação reguladora da época: 1925-1975. Dissertação de Mestrado Coppe/UFRJ.

SANTOS, F. A. N. 1934. Meios de Transporte no Rio de Janeiro. História e legislação. Rio de Janeiro: Typ. do Jornal do Commercio Rodrigues \& C. 2 vol.

SILVA, Tomaz Tadeu. 2006. A produção social da identidade e da diferença. In; Silva, Tomaz Tadeu et alii. Identidade e diferença. A perspectiva dos estudos culturais. Petrópolis: Vozes. 
SIMÕES, Ruth Mattos Almeida. 1952-53. Contribuição à geografia carioca: notas sobre a geografia do bairro de Laranjeiras. Anais da Associação de Geógrafos Brasileiros 7 (1). pp. 171-206.

VAZ, Lílian F. 2002. Modernidade e moradia.- habitação coletiva no Rio de Janeiro séculos XIX e XX. Rio de Janeiro: Sete Letras. 2002.

VELHO, Gilberto. 1989. A utopia urbana. Rio de Janeiro: Zahar.

VILLAÇA, Flávio. 1998. O espaço intra-urbano no Brasil. São Paulo: Studio Nobel Editora, Fapesp, Lincoln Institute. 1998.

2000. Segregation in the Brazilian metropolis. International

Seminar on Segregation in the City. Lincoln Institute of Land Policy. Canbridge, Mass. Disponível em flaviovillaca.arq.br 